\title{
Elaboration of a nomogram to predict non sentinel node status in breast cancer patients with positive sentinel node, intra-operatively assessed with one step nucleic acid amplification method
}

\author{
F. Di Filippo ${ }^{1 *}$, D. Giannarelli ${ }^{1}$, C. Bouteille ${ }^{2}$, L. Bernet ${ }^{3}$, R. Cano ${ }^{4}$, G. Cunnick ${ }^{5}$ and A. Sapino ${ }^{6,7}$
}

\begin{abstract}
Backgrounds: Tumor-positive sentinel node(SLN) biopsy results in a risk of nonsentinel node metastases in case of micro and macro metastases ranging from 20 to $50 \%$, respectively. Therefore, most patients underwent unnecessary axillary lymph node dissections.

Thus, the development of a mathematical model for predicting patient-specific risk of non sentinel node(NSLN) metastases is strongly warranted.

Methods: The following parameters were recorded:

- Clinical: hospital, age, medical record number

- Bio-pathological: tumor (T) size, grading (G), multifocality, histological type, LVI, ER-PR status, HER-2, ki67, molecular classification (luminal A, luminal B, HER2 like, triple negative)

- Sentinel and nonsentinel lymph node related: number of removed SLNs, number of positive and negative SLNs, copy number of positive sentinel nodes, ratio: number of positive SLNs to number of removed SLNs, number of removed and number of positive nodes after ALND. A total of 2460 patients have been included in the database.
\end{abstract}

All the patients have been provided by the authors of this paper.

Results: Multivariate logistic regression analysis demonstrated that only the number of a CK19 mRNA copies $(p<0.0001)$, T size $(p<0.0001)$ and LVI $(p<0.0001)$ were associated with NSN metastases.

The discrimination of the model, quantified with the area under the receiver operating characteristics curve, was 0.71 ( $95 \%$, C.I. 0.69-0.73), thus confirming a good level of reliability.

Conclusions: The nomogram may be employed by the surgeon as a decision making tool on whether to perform an intraoperative axillary lymph node dissection on breast cancer patients with SLN positive.

The large population employed and the standardized method of measuring the value of CK19 mRNA copies are appropiate prerequisites for a reliable nomogram.

Keywords: Nomogram, Non Sentinel Node status, OSNA method, CK19 mRNA number copies

\footnotetext{
* Correspondence: difilippo@ifo.it

${ }^{1}$ Regina Elena National Cancer Institute, Via Elio Chianesi 53, 00134 Rome, Italy

Full list of author information is available at the end of the article
}

(C) 2015 Di Filippo et al. Open Access This article is distributed under the terms of the Creative Commons Attribution 4.0 International License (http://creativecommons.org/licenses/by/4.0/, which permits unrestricted use, distribution, and reproduction in any medium, provided you give appropriate credit to the original author(s) and the source, provide a link to the Creative Commons license, and indicate if changes were made. The Creative Commons Public Domain Dedication waiver (http://creativecommons.org/publicdomain/zero/1.0/) applies to the data made available in this article, unless otherwise stated. 


\section{Background}

Breast cancer is one of the most frequent neoplasm in women, generally treated with quadrantectomy or mastectomy [1].

Sentinel lymph node (SLN) biopsy is a highly accurate predictor of overall axillary status and has become the standard axillary staging method for the last 15 years in breast cancer $(\mathrm{BC})$ patients who are confirmed clinically negative for lymph node metastases $[2,3]$. In the case of negative SLN, patients can safely avoid axillary lymph node dissection (ALND), thus preventing associated morbidity [4]. However, approximately 50-70 \% of patients with positive SLN have no additional positive nodes, suggesting that it may be possible to avoid ALND in selected patients $[5,6]$. Taking these considerations into account, an accurate estimate of the likelihood of additional node metastases may be of paramount importance when deciding further treatment. At the present time, the intraoperative decision on, whether to perform ALND or not, is often only based on the positivity of the SLN. In order to assess the SLN status more rapidly, a semi-automated molecular method called the one step nucleic acid amplification (OSNA) assay has recently been made available [7-11]. On the basis of these considerations, the European OSNA Committee decided to develop a new nomogram able to predict the non sentinel node (NSN) status, including the number of CK 19 mRNA copies as the most powerful parameter. The aim of the study was to report the results of the retrospective phase of the Nomogram Project, as the validation phase is ongoing.

\section{Methods}

The European OSNA Users Committee decided to develop a Nomogram Project with the following aims:

- To create new predictive factors for NSN positivity (copy number of CK19 mRNA) as well assessing the conventional histopathological parameters.

- To develop a user-friendly nomogram to predict NSN positivity based on the CK19 mRNA copy determined by OSNA assay tested in large patient population.

Our study population only included cases that fulfilled the following criteria: primary invasive cT1-3 BC with clinically and radiological (preoperative sonogram) negative axilla; no prior systemic treatment, or axillary surgery; successful SLN biopsy in which metastatic disease was identified by OSNA; and ALND with at least 10 nodes examined.

The following parameters were recorded:

- Clinical: hospital, age, medical record number
- Bio-pathological: tumor size, grading, multifocality, histological type, LVI, ER-PR status, HER-2, ki67, molecular classification (luminal A, luminal B, HER2 like, triple negative)

- SLN and NSN related: number of removed SLNs, number of positive and negative SLNs, copy number of positive SLNs, ratio: number of positive SLNs to number of removed SLNs, number of removed and number of positive nodes after ALND. A total of 2460 patients have been included in the database.

The biopathological parameters included in the database are shown in Tables 1 and 2 .

Twenty-two European centers contributed to the enrollment of patients between January 2008 and February 2013; 2460 patients made up the body of nomogram.

\section{Sentinel Lymph Node sampling method}

SLNs were identified using technetium $99 \mathrm{~m}$ - labeled, nanosized, human serum albumin colloids. To avoid any contamination during tumor manipulation, SLNs were surgically excised before breast surgery and sent on ice to the Pathology Department.

Each SLN was weighed and measured. SLNs weighing less than $50 \mathrm{mg}$ were excluded from the study. SLNs weighing more than $600 \mathrm{mg}$ were cut in two or more pieces and processed as separate nodes.

\section{One Step Nucleic Acid Amplification}

The OSNA assay was performed according to the manufacturer's instructions (Sysmex, Kobe, Japan). In short, the SLN was homogenized in $4 \mathrm{ml}$ of the LINORHAG homogenizing buffer (Sysmex) on ice. A small aliquot was used for automated real- time amplification of CK19 mRNA via reverse transcription loop-mediated isothermal amplification (RT-LAMP) with the ready-to use LYNOAMP reagent kit (Sysmex) on the RD-100i (Sysmex).

It was possible to analyze up to 4 SLNs in one run.

The degree of amplification was detected via a byproduct of the reaction, i.e. magnesium-pyrophosphate. After use, the excess lysate was stored at minus $80{ }^{\circ} \mathrm{C}$. A lysate with CK19 mRNA copy number/ $\mu$ l less than 250 (a) was regarded as negative (score-); from 250 to 5000 (b) as positive (score + ), and greater than 5000 (c) (score ++ ). The OSNA results were immediately communicated by telephone to the surgeon within 30-40 min. For statistical analysis, in case of two or more SLNs, the SLN with the greatest CK19 mRNA copies was chosen.

When there was a positive OSNA result, both for micrometastases $(+)$ and macrometastases $(++)$ the patients underwent an immediate ALND. ITC are not detected by OSNA method. This is not a limitation because patients 
Table 1 Clinicopathologic characteristic of patients

\begin{tabular}{|c|c|c|}
\hline Characteristics & $\mathrm{N}$ of patients & Percent \\
\hline \multicolumn{3}{|l|}{ HYSTOLOGY } \\
\hline IDC & 2140 & 87.0 \\
\hline ILC & 320 & 13.0 \\
\hline \multicolumn{3}{|l|}{ GRADING } \\
\hline G1 & 389 & 15.8 \\
\hline G2 & 1395 & 56.7 \\
\hline G3 & 676 & 27.5 \\
\hline \multicolumn{3}{|l|}{ ER } \\
\hline pos & 2213 & 90.0 \\
\hline neg & 247 & 10.0 \\
\hline \multicolumn{3}{|l|}{$\mathrm{PgR}$} \\
\hline pos & 1984 & 80.6 \\
\hline neg & 476 & 19.4 \\
\hline \multicolumn{3}{|l|}{ HER2 } \\
\hline pos & 162 & 6.5 \\
\hline neg & 2298 & 93.5 \\
\hline \multicolumn{3}{|l|}{ Ki67 } \\
\hline low & 1271 & 51.7 \\
\hline high & 1189 & 48.3 \\
\hline \multicolumn{3}{|l|}{$\mathrm{T}$} \\
\hline$\leq 12$ & 638 & 25.9 \\
\hline$\geq 13-18$ & 676 & 27.5 \\
\hline$\geq 19-25$ & 642 & 26.1 \\
\hline$>25$ & 504 & 20.5 \\
\hline \multicolumn{3}{|l|}{ TYPE ${ }^{a}$} \\
\hline multiple & 378 & 15.4 \\
\hline single & 2082 & 84.6 \\
\hline \multicolumn{3}{|l|}{ LVI } \\
\hline no & 1397 & 56.8 \\
\hline yes & 1063 & 43.2 \\
\hline Luminal A & 1185 & 48.1 \\
\hline Luminal B & 982 & 39.9 \\
\hline HER2-like & 46 & 1.9 \\
\hline Triple Negative & 247 & 10.1 \\
\hline
\end{tabular}

with positive SN for ITC are no longer submitted to ALND.

Axillary NSNs were routinely examined by H\&E.

\section{Statistical analyses}

The outcome of our nomogram was the presence of positive nodes in the axillary dissections following OSNA evaluation in the population defined above. We identified a list of potential covariates that may predict this outcome, thus the endpoint was a binary outcome (presence versus
Table 2 Characteristics of sentinel node and non sentinel node

\begin{tabular}{|c|c|c|}
\hline & Number & Percent \\
\hline \multicolumn{3}{|l|}{$\mathrm{N}^{\circ}$ of SLN Examined } \\
\hline 1 & 1273 & 51.7 \\
\hline 2 & 801 & 32.6 \\
\hline 3 & 277 & 11.3 \\
\hline 4 & 88 & 3.5 \\
\hline 5 & 17 & 0.7 \\
\hline 6 & 4 & 0.2 \\
\hline \multicolumn{3}{|l|}{$\mathrm{N}^{\circ}$ of positive SLN } \\
\hline 1 & 1765 & 71.8 \\
\hline 2 & 527 & 21.4 \\
\hline 3 & 136 & 5.5 \\
\hline 4 & 29 & 1.2 \\
\hline 5 & 3 & 0.1 \\
\hline SLN Micrometastases & 977 & 39.7 \\
\hline SLN Macrometastases & 1483 & 60.3 \\
\hline Median (range) & $14(2-47)$ & \\
\hline $\mathrm{N}^{\circ}$ of NSLNs removed mean & 14.8 & \\
\hline $\mathrm{N}^{\circ}$ of positive NSLNs & 829 & 33.7 \\
\hline Median (range) & $2(1-30)$ & \\
\hline Mean & 3.2 & \\
\hline \multicolumn{3}{|c|}{ N Ratio: No SLN / N SLN removed } \\
\hline$<0.25$ & 23 & 0.9 \\
\hline $0.25-0.50$ & 491 & 20.0 \\
\hline $0.50-1.00$ & 111 & 4.5 \\
\hline 1.00 & 1835 & 74.6 \\
\hline \multicolumn{3}{|c|}{$\mathrm{N}^{\circ}$ of Copies (Highest copy number) } \\
\hline$\leq 1500$ & 615 & 25.0 \\
\hline$>1500-12,000$ & 636 & 25.9 \\
\hline$>12,000-111,000$ & 608 & 24.7 \\
\hline$>111,000$ & 601 & 24.4 \\
\hline \multicolumn{3}{|c|}{$N^{\circ}$ of Copies (Total Tumor Load) } \\
\hline$\leq 1500$ & 607 & 24.7 \\
\hline$>1500-12,000$ & 625 & 25.4 \\
\hline$>12,000-111,000$ & 612 & 24.9 \\
\hline$>111,000$ & 616 & 25.0 \\
\hline
\end{tabular}

absence of at least one positive node other than SLN) and the association with the covariates was analyzed using a logistic linear model. Continuous variables (number of CK19 mRNA copies and T size expressed in $\mathrm{mm}$ ) were categorized using quartiles. We investigated the role of each variable and estimated the Odds Ratio along with the $95 \%$ confidence interval; independent factors were then identified using a stepwise forward likelihood ratio method. 
Discrimination ability was assessed by ROC analysis and predictive accuracy was measured by the AUC reported with its $95 \%$ confidence interval. Calibration was evaluated by reviewing the plot of predicted probabilities versus the actual probabilities. Well calibrated models have a linear relationship with a slope of 1 and an intercept of 0 . Thus, a linear regression coefficient between predicted and observed values was estimated.

The resulting model will be validated in a prospective series. All the analyses were performed using IBM SPSS version n. 20 [12].

\section{Ethical consideration}

The patient data was anonymously gathered retrospectively with no influence on patient therapy. The Nomogram project was approved by Ethical Committee of each participating institution.

\section{Results}

Table 1 shows the clinical and bio-pathological characteristics of the patients.

The mean and median ages were 56 and 54, respectively ranging between 22 and 90 years.

The vast majority of the patients were affected with infiltrating ductal carcinoma (87.0\%). Most of them had an intermediate $(56.7 \%)$ or high grade tumors $(27.5 \%)$. Both Estrogen (ER) and Progesterone (PgR) receptors were positive in 90 and $80.6 \%$, respectively, whereas HER2 was positive only in $6.5 \%$ of the patients. Ki67 was high in $48.3 \%$ and LVI was present in $43.2 \%$ of the patients. These parameters represent the new molecular classifications of breast cancer that allow not only to identify patients at a higher risk of relapse but may also guide postoperative therapies $[13,14]$.

Tumor size was divided in quartiles, the cut-offs being 12, 18 and $25 \mathrm{~mm}$.

The mean and median tumor sizes were 20.3 and $18 \mathrm{~mm}$, respectively, ranging between 0.8 and $50 \mathrm{~mm}$.

The SLNs and NSLNs characteristics are reported in Table 2. Patients with micro or macrometastases in the SLNs were 977 (39.7\%) and 1483 (60.3\%), respectively.

The median number of examined and positive SLNs was 1, one SLN was examined in 1273 patients (51.7\%); 2 in $801(32.6 \%) ; 3$ in 277 (11.3\%); 4 in 88 (3.5\%); 5 in $17(0.7 \%)$; 6 in $4(0.2 \%)$.

1765 patients $(71.8 \%)$ had only 1 positive SLN, 527 (21.4\%) had two, 136 (5.5\%) had three, 29 (1.2\%) had four and $3(0.1 \%)$ had five. NSLNs were positive in 829 patients $(33.7 \%)$, found both in patients with SLN micrometastases $(22 \%)$ or macrometastases $(78 \%)$. The median and mean number of positive NSLNs were 2 and 3.2, respectively, ranging between 1 and 30 .

The mean and median number of NSLNs removed were 14.8 and 14, respectively. The number of CK19 mRNA copies was divided in quartiles in order to obtained a better stratification of the patients.

In Table 3 the results of univariate and multivariate analyses are reported.

Logistic regression model showed that grading $(p<$ $0.0001)$, Ki67 $(p<0.01)$, type $(p<0.001)$, T size $(p<0.0001)$, size of metastatic foci (micro or macrometastases) in the SLN $(p<0.0001)$ and number of CK19 mRNA copies $(p<0.0001)$ were associated with positive NSN status.

Multivariate logistic regression using a Cox model analysis demonstrated that only the number of CK19 mRNA copies $(p<0.0001)$, T size $(p<0.0001)$ and LVI $(p<0.0001)$ maintained their independent value, and therefore they would be useful to construct the nomogram. We wanted to build a nomogram that the surgeon could utilize during the operation, therefore LVI was excluded because its unreliability was assessed in preoperative core biopsy only.

According to the clinical-pathological characteristics of our patients, the predicted probability of NSN positivity ranges between 9.9 and $64.3 \%$.

One of the main aim of nomogram is to identify the subgroup of patients with a low risk of NSN involvement [15]. When calculating the number of patients with a probability of metastatic NSN $\leq 10 \%$, predicted by the nomogram, 212 patients could be identified in this subset. Among these patients, 196 patients were truly negative and only 16 (7.5 \%) were falsely negative. It must be emphasized that the percentage of $7.5 \%$ is, perfectly superimposable to false negative rate of SLN biopsy normally quoted at $5-10 \%[16,17]$.

The model showed a sensitivity of $98.1 \%$ and a specificity of $19 \%$, whilst the positive and negative predict values were 36.2 and $92.5 \%$, respectively.

The discrimination of the model, quantified with the area under receiver operating characteristic (ROC) curve was 0.71 (95 \% c.i. $0.69-0.73$ ) showing a good level of discrimination (Fig. 1).

The model performed well and correctly both in low and in high risk cases as shown in the calibration plot. The linear regression model between has a slope of 0.98 (95\% c.i. $0.89-1.07)$ and a constant of 0.01 (95 \% c.i. -0.03-0.04) between predicted and actual probability (Fig. 2).

The significant variables were then incorporated into a nomogram to predict NSN status (Fig. 3).

\section{Discussion}

It is well known that SLN micro- and macrometastases are associated with mean NSN positivity rate of 20 and $50 \%$, respectively. Consequently, the dilemma for surgeons still persists in how to avoid unnecessary ALND and how to identify patients at low risk of NSN positivity. 
Table 3 Results of Univariate and Multivariate Analysis

\begin{tabular}{|c|c|c|c|c|}
\hline \multicolumn{3}{|l|}{ Univariate analysis } & \multicolumn{2}{|c|}{ Multivariate analysis } \\
\hline & OR (95 \% c.i.) & $P$ & OR (95 \% c.i.) & $P$ \\
\hline HYSTOLOGY & & 0.44 & & \\
\hline CDI vs CLI & $0.90(0.69-1.17)$ & & & \\
\hline GRADING & & 0.001 & & \\
\hline G2 vs G1 & $1.45(1.12-1.87)$ & 0.005 & & \\
\hline G3 vs G1 & $1.74(1.32-2.31)$ & $<0.0001$ & & \\
\hline ER & & 0.27 & & \\
\hline Pos vs neg & $1.19(0.87-1.61)$ & & & \\
\hline $\mathrm{PgR}$ & & 0.09 & & \\
\hline Pos vs neg & $1.22(0.97-1.53)$ & & & \\
\hline HER2 & & 0.11 & & \\
\hline Pos vs neg & $0.73(0.50-1.07)$ & & & \\
\hline Ki67 & & 0.01 & & \\
\hline High vs low & $1.29(1.06-1.56)$ & & & \\
\hline $\mathrm{T}$ & & $<0.0001$ & & $<0.0001$ \\
\hline $13-18$ vs $<12$ & $1.31(1.02-1.67)$ & 0.03 & $1.10(0.85-1.43)$ & 0.45 \\
\hline $19-25$ vs $<12$ & $2.04(1.60-2.60)$ & $<0.0001$ & $1.73(1.34-2.23)$ & $<0.0001$ \\
\hline$>25$ vs $<12$ & $2.70(2.10-3.48)$ & $<0.0001$ & $2.22(1.70-2.90)$ & $<0.0001$ \\
\hline TYPE* & & 0.001 & & \\
\hline Multiple vs single & 1.55 (1.19-2.02) & & & \\
\hline LVI & & $<0.0001$ & n.c. & \\
\hline Yes vs No & $2.88(2.37-3.49)$ & & & \\
\hline COPIES & & $<0.0001$ & & \\
\hline Macro $(>5000)$ vs Micro $(<=5000)$ & $3.57(2.95-4.32)$ & & & \\
\hline COPIE & & $<0.0001$ & & $<0.0001$ \\
\hline $1500-12,000$ vs $<1500$ & $2.15(1.62-2.85)$ & $<0.0001$ & $2.15(1.60-2.87)$ & $<0.0001$ \\
\hline $12,000-111,000$ vs $<1500$ & $4.26(3.24-5.62)$ & $<0.0001$ & $4.14(3.12-5.49)$ & $<0.0001$ \\
\hline$>111,000$ vs $<1500$ & $7.18(5.46-9.45)$ & $<0.0001$ & $6.86(5.18-9.01)$ & $<0.0001$ \\
\hline MOLECULAR SUBTYPE & & 0.05 & & \\
\hline Luminal A vs triple neg & $1.09(0.76-1.56)$ & 0.64 & & \\
\hline Luminal B vs triple neg & $1.39(0.97-2.01)$ & 0.07 & & \\
\hline Her2 vs triple neg & $0.76(0.32-1.80)$ & 0.54 & & \\
\hline
\end{tabular}

Recently, ASCO guidelines for SLNB and ALND have been published, indicating the patients with micro and macrometastases (only those that meet Giuliano criteria) may avoid ALND, but many controversies still remain [18]. The Z0011 Trial that randomized patients to observation or ALND after positive SLN, failed to reach its target accrual. However, the analysis restricted to only 856 patients seemed to demonstrate no differences in disease-free and overall survival between the two groups [19]. But the limited number of patients together with the fact that $97 \%$ of patients received systemic chemotherapy and axillary radiotherapy (89\%) obscures the reliability of the results. Moreover, the results of this study cannot be applied to subsets of patients like young women ( $<50$ years), patients undergoing mastectomy, patients with lobular carcinoma or hormone receptor negative tumours or HER2 positive tumours, due to being underrepresented in Z0011 study. Finally in 2012, the CAGS/ACS Based Review in Surgery Committee examined the Z0011 trial because its results might be "practice changing". A great deal of biases were found and the final conclusion was: "Should the results of Z0011 change practice? Owing to its methodological limitations, if we had to depend on Z0011 alone, the standard of care following positive sentinel node is still an ALND" [20]. The same conclusion was reached by a 

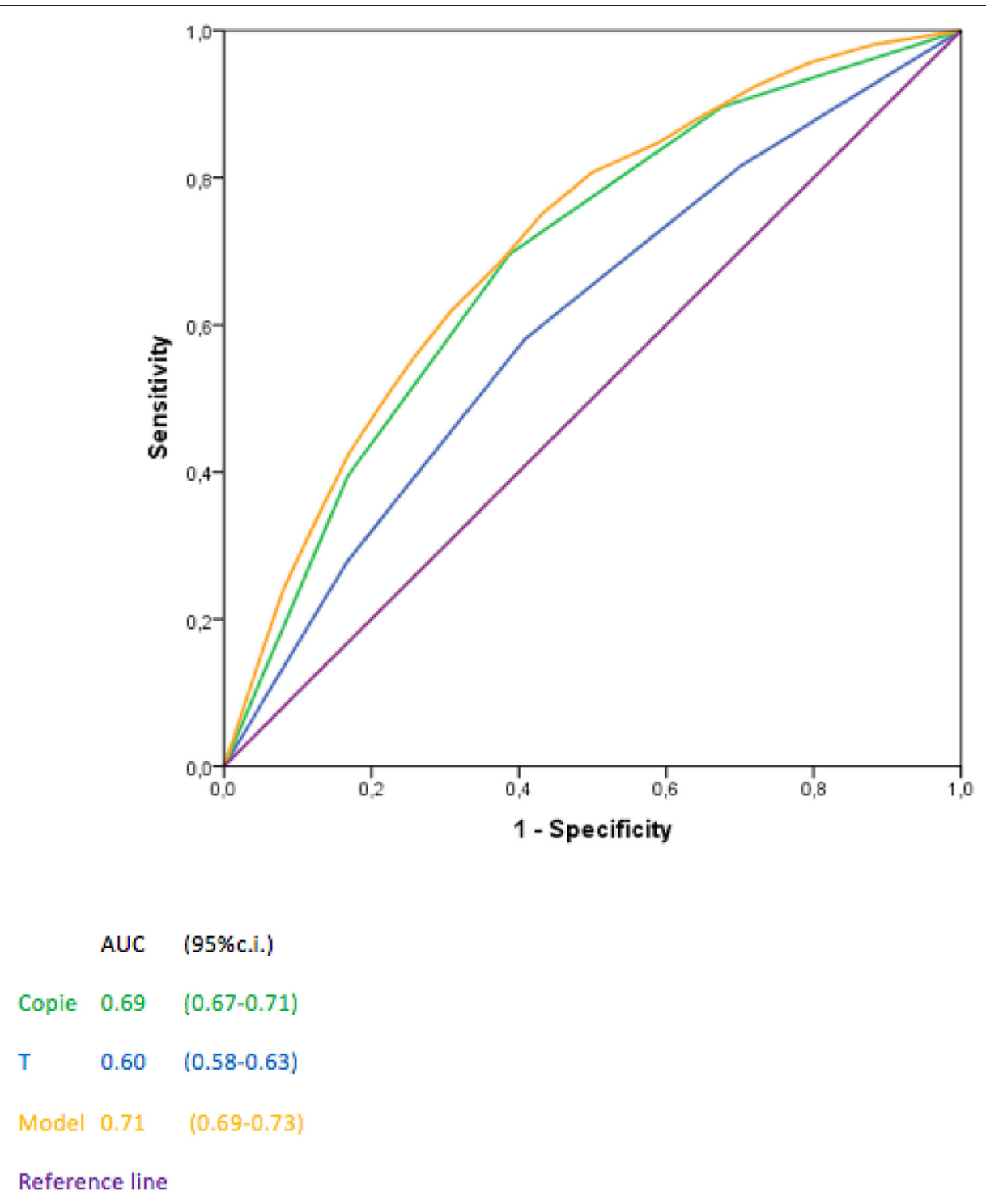

Fig. 1 ROC curves of number of CK19 mRNA, T size (quartiles) and the model containing these two variables

German, Austrian and Swiss (D, A, CH) consensus panel in 2013 [21].

Recently, the prospective randomized IBCSG23-01 trial has been published [22]. Only patients with micrometastases were randomized to either ALND or no further treatment in patients with positive SLN.

The results of this study demonstrated no differences between the two arms both in terms of disease-free and of overall survival.

Some challenges, however, still exist regarding this study. Patients accrual stopped prematurely and only 933 out of 1960 patients were enrolled, therefore the study was underpowered.

The patient population had a very good prognosis. In fact, sentinel tumor size $\leq 1 \mathrm{~mm}$ was present in $69 \%$ of the patients. As a result, the incidence of additional positive NSN in axillary dissection group was $13 \%$, very similar to that found in case of ITCs metastases in SLN. This is also because the author included ITCs in the group of micrometastases. A clear correlation between the size of micrometastases (less or greater than $1 \mathrm{~mm}$ ) and positive NSNs was clearly demonstrated by Rahusen and Viale $[23,24]$. Their results confirm that the presence in the study of $69 \%$ of patients with SLN micrometastases $\leq$ $1 \mathrm{~mm}$ is a great bias. The median 5-years follow-up is too short to assess the real incidence of axillary recurrence in this study. In NSABP-B6, $20 \%$ of nodal recurrences after lumpectomy and $24 \%$ of nodal recurrences after lymphadenectomy and radiotherapy occurred after 5 years [25]. These data are very consistent with the Dutch Mirror 


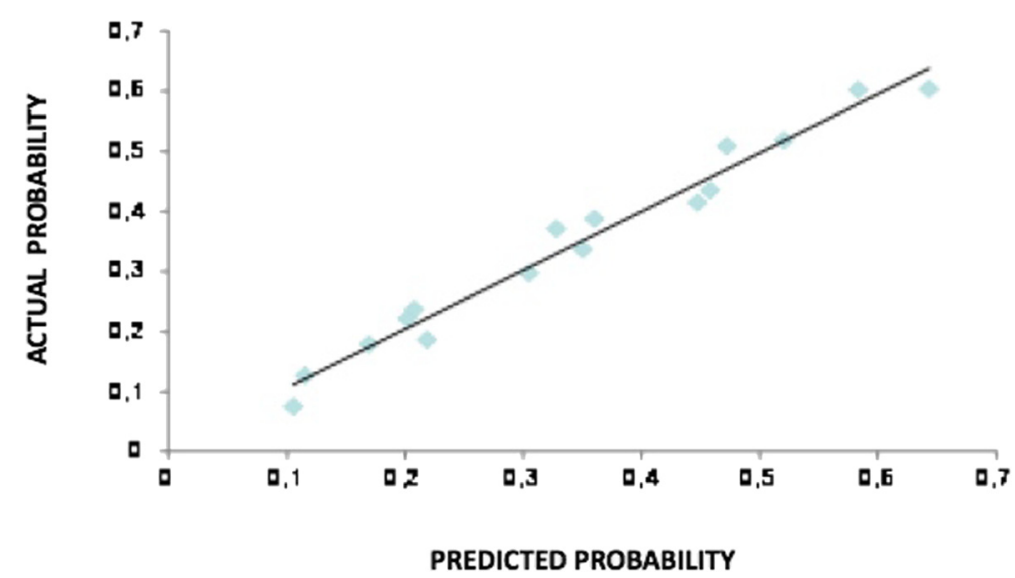

Fig. 2 The model performs well and correctly both at low and in high risk cases as shown in calibration plot. The linear regression model has a slope of 0.98 ( $95 \%$, C.I. 0.89-1.07) and a constant of 0.01 between predicted and actual probabilities (95\%, C.I. 0.03-0.04)

study that demonstrated an increased recurrence rate in patients with micrometastases in the SLN not undergoing ALND [26].

Taking into account these considerations, accurate estimates of the likelihood of additional nodal metastases may be of paramount importance in the decision making process regarding further treatment. Nomograms might be valid prediction tools for surgeons to select patients that significantly benefit from an ALND after positive SLN.

The European OSNA Users Committee decided to collect a high number of patients use whose SLNs were all assessed with OSNA. In fact, our nomogram elaborated 2460 patients.
To the best of our knowledge, this is the largest prospective series in which patients with micrometastases $(+)$ and macrometastases $(++)$, detected by the OSNA assay, underwent immediated ALND.

Table 3 shows that multivariate regression Cox analysis selected the number of CK19 mRNA copies, T size and LVI as independent prognostic factors. LVI was not employed to develop the nomogram for its unreliability to assess this parameter with only a preoperative core biopsy. OSNA classifies SLN micrometastases when the number of CK19 mRNA copies ranges between 250 and 5000; whereas the number of copies > 5000 identifies macrometastases.

Therefore, for both micro and macro-metastases there is a wide range of number of copies, and according to

\section{To predict probability of positive non sentinetnode add up the corresponding number to calculate the total score and find the correspondent probability in the table at the bottom:}

\begin{tabular}{ll} 
Factor & Point \\
\hline Tumor size $<=12 \mathrm{~mm}$ & 0 \\
Tumor size $>12 \mathrm{~mm}$ and $<=18 \mathrm{~mm}$ & 0.09 \\
Tumor size $>18 \mathrm{~mm}$ and $<=25 \mathrm{~mm}$ & 0.54 \\
Tumor size $>25 \mathrm{~mm}$ & 0.79 \\
Number of copies $<=1500$ & 0 \\
Number of copies $>1500$ and $<=12000$ & 0.76 \\
Number of copies $>12.000$ and $<=111.000$ & 1.34 \\
Number of copies $>111.000$ & 1.85
\end{tabular}

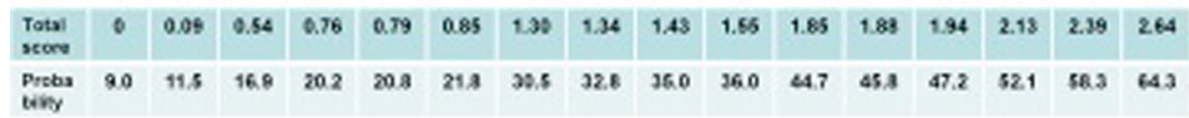

Fig. 3 Nomogram to calculate the risk percentage of NSN positivity. The score of each of the 2 variables are summed and reported on the total score raw, immediately below the percentage of NSN positivity is identified 
the number of copies, patients may have different probabilities of positive NSN [11].

In our nomogram, we used the number of copies as a continuous variable divided in quartiles in order to have approximately the same number of patients in each subgroup with a more reliable patient distribution. The use of SLN size as a continuous variable improved the capacity of nomogram to accurately predict the NSN involvement in patients with positive SLN, as demonstrated by Mittendorf [27].

The availability of a molecular method which provides less subjective and quantitative results may be a useful tool in this context. We also evaluated $\mathrm{T}$ size as a continuous variable dividing patients in quartiles to obtain a better distribution.

The association of tumor size with the likelihood of NSN metastasis has been documented in numerous studies [15, 28-36].

It is readily apparent that the two parameters chosen for our nomogram reflect the greatest probability to identify patients with the NSN metastasis.

There are several parameters that permits to evaluate the reliability of a nomogram.

\section{Discrimination}

In our nomogram the AUC is $0.71(0.69-0.73)$ which is considered a good value of discrimination and is consistent with the best nomograms published so far [37-43].

\section{Calibration}

Calibration determines the distance between predicted outcome and actual outcome, and has a higher clinical significance than discrimination [27, 37].

In our nomogram, the mean difference between predicted and calibrated probabilities was $2.3 \%$, with a maximum difference of $4.0 \%$ (Fig. 2). This information is of clinical utility because it gives the opportunity for the clinicians to inform the patient regarding both the predicted probability of NSN metastases and the range of probability.

\section{False negative rate}

It must be emphasized that our nomogram was able to identify 212 patients with a risk of NSN metastases $\leq 10$ $\%$. Only 16 patients were FN (i. e. presence of metastases) in NSLNs. Therefore, the FN rate is $7.5 \%$, thus confirming the validity of the nomogram to identify patients that may omit ALND. This makes both the surgeon comfortable in the decision making process as well as the patient to accept this decision.

The multivariate logistic regression analysis showed that the number of copies is an independent predictor of metastatic NSLNs after adjusting for T size (Fig. 1).
It must be stressed that the number of copies is assessed intra-operatively. Therefore, the surgeon may decide on whether to perform an ALND or not in the same operation, avoiding the psychological impact of a second operation.

However the result of this nomogram are currently under external validation to test reproducibility of the model on a large series of independent prospective data. This method remains the best choice in validating the proposed nomogram and in making a reliable instrument available.

\section{Conclusions}

In conclusion, there is still ongoing discussion and debate among breast cancer surgeons regarding the need to perform completion ALND in patients with positive SLN. This nomogram incorporating SLN tumour burden, defined by OSNA method, is another tool that can be utilized by surgeons to more effectively counsel individual patients, thereby personalizing the surgical treatment of breast cancer and using this information intra-operatively.

\begin{abstract}
Abbreviations
ALND: Axillary lymph node dissection; BC: Breast cancer; ER: Estrogen receptor; ITC: Isolated tumor cell; LVI: Lymphovascular invasion; NSN: Non sentinel node; OSNA: One step nucleic acid amplification; PgR: Progesterone receptor; RT-LAMP: Reverse transcription loop-mediated isothermal amplification; ROC: Operating characteristics curve; SLN: Sentinel lymphonode.
\end{abstract}

\section{Competing interests}

The authors declare that they have no competing interests.

\section{Authors'contributions}

The paper has been carried out on behalf of the Clinical Trial Consortium: Dr. C. M. Antonacci, d.sa E. Omodeo Zorini, Azienda Ospedaliera, Polo Universitario, Pathology department, Az. Osp. L. Sacco - Milano. Dr. S. Buglioni PhD, V. D'Alicandro PhD, Pathology Department, Regina Elena National Cancer Institute, Rome, Di Filippo S. MD, Galanou J. MD, Department of Senology, Regina Elena National Cancer Institute, Rome. Prof. R. Boldorini, d.sa G. Nicosia, Pathology department, Amedeo Avogadro del Piemonte Orientale University, Novara. Dr. T. Perin, MD- Department of Pathology-Breast Unit, A. Carbone, MD-Department of Pathology, S. Massarut, MD- Department of Breast Surgery- Breast Unit, Aviano-IRCSS- National Cancer Institute, Aviano (PN). Dr. Corrado Tinterri, Breast Unit, Humanitas Clinical and Research Center, Prof. M. Roncalli, Dr. Luca Di Tommaso, Medical Biotecnology department, Pathology department, Humanitas Clinical and Research Center, Rozzano (MI). Dr. A. Gianatti, dr E. Candiago, d.sa L. Cattaneo, d.sa L. Licini, Pathology department PAPA GIOVANNI XXIII Hospital, Bergamo. Castellano I., Deambrogio C., Department of Medical Sciences, University of Turin, Torino. Dr. Truglia M. C ., dr. Giannini A., Pathology department and dr. A. Battaglia general surgery Misericordia e Dolce Hospital, Prato. Dr. Di Sclafani E., Dr. Vegezzi PG., d.sa Malinverno L., dr Zulian E., dr E. Biella, Senology department Sacra Famiglia Fatebenefratelli Hospital, Erba. Dr. Drago S., Department of Surgery, D.sa Baldini UOC Pathology department, San Filippo Neri Hospital, Rome. Dr. Palmieri F., Surgery department, dr Guaragni M., dr. C. Agazzi, Pathology department, S. Anna Clinical Institute, Brescia. Prof. Michel Peoc'h, University Hospital, Saint Etienne. Dr Florence Godey, Centre Eugene Marquis, Rennes. Dr. Cecile Bendavid, Centre

Eugene Marquis, Rennes. Dr. Jean Michel Piquenot, Centre Henri Becquerel, Rouen. Dr. Antonio Piñero-Madrona, HU "Virgen de la Arrixaca", Murcia. Dr. Francisco Vicente-García, Complejo Hospitalario de Navarra, Pamplona. Dr. Jose Antonio Alberro, Instituto Onkologikoa, San Sebastian. Dr. Rosa Barbella, Manuel Atiénzar, HU de Albacete. Dr. Luis Carrasco-Gonzáles, HU JM Morales Meseguer, Murcia. Dr. Begoña Miguel-Martínez, HU "General Yagüe", Burgos. Dr. Julia Giménez-Climent, Instituto Valenciano de Oncología, Valencia. Dr. Basilio 
Dueñas, Complejo Hospitalario de Jaén. Dr. Pedro Marín-Rodriguez, HU “Reina Sofía", Murcia. Dr. Amparo Viguri-Díaz, Hospital Txagorritxu, Vitoria. Dr. Ángel Concha, HU "Virgen de las Nieves", Granada. Dr. David Hardisson, HU "La Paz", Madrid. Dr. Jesús Acosta, Hospital "Santa Lucía", Cartagena. Dr. Octavi Burgués, Hospital Clínico de Valencia. Dr. Beatriz Torio, Hospital "Rio Carrion", Palencia. Dr. Jesús Razquín, Hospital "Virgen de la Luz", Cuenca. Dr. Amalia Moreno, Hospital de Fuenlabrada, Madrid. Dr. Irune Ruiz, Hospital de Donosti, San Sebastián. Dr. Carmen González, Hospital "Puerta de Hierro", Madrid. Dr. Angeles Torres Nieto, Hospital 'Rio Hortega", Valladolid. Dr. Pedro Luís Fernández Díaz, Hospital Clinic de Barcelona. Dr. GT Layer, MW Kissin, P Jackson and TE Irvine; Guildford Breast Unit. Dr. Zenon Rayter; North Bristol NHS Trust. Dr. Anil Desai, Mr Sudeendra Doddi; Princess Royal University Hospital, Farnborough, Kent. Dr. Wendy Sotheran; St Richard's Hospital, Western Sussex Hospitals Trust. Dr. Siobhan Laws; Hampshire Hospitals NHS Foundation Trust.

\section{Acknowledgements}

We acknowledge Dr. Giles Cunnick and Tania Merlino for writing assistence, Dr. M. Zaenkert for general support.

\section{Author details}

Regina Elena National Cancer Institute, Via Elio Chianesi 53, 00134 Rome, Italy. ${ }^{2}$ Clinique Mutualiste, Saint Etienne, France. ${ }^{3}$ Hospital de Xàtiva, Valencia, Spain. ${ }^{4}$ Hospital de Alzira, Valencia, Spain. ${ }^{5}$ Wycombe General Hospital, Buckinghamshire, England. 'Istituto di Candiolo - IRCCS, Fpo-Ircc., Turin, Italy. ${ }^{7}$ Dept of Medical Sciences - University of Turin, Turin, Italy.

Received: 21 July 2015 Accepted: 19 October 2015

Published online: 04 November 2015

\section{References}

1. Piscitelli P, Barba M, Crespi M, Di Maio M, Santoriello A, D'Aiuto M, et al. The burden of breast cancer in Italy: mastectomies and quadrantectomies performed between 2001 and 2008 based on nationwide hospital discharge records. J Exp Clin Cancer Res. 2012;31:96

2. Veronesi U, Paganelli G, Viale G, Luini A, Zurrida S, Galimberti V, et al. Sentinel-lymph-node biopsy as a staging procedure in breast cancer: update of a randomised controlled study. Lancet Oncol. 2006;7:983-90.

3. Lyman GH, Giuliano AE, Somerfield MR, Benson 3rd AB, Bodurka DC, et al. American Society of Clinical Oncology guideline recommendations for sentinel lymph node biopsy in early-stage breast cancer. J Clin Oncol. 2005:23:7703-20

4. Fleissig A, Fallowfield L, Langridge Cl, Johnson L, Newcombe RG, Dixon JM, et al. Post-operative arm morbidity and quality of life. Results of the ALMANAC randomised trial comparing sentinel node biopsy with standard axillary treatment in the management of patients with early breast cancer. Breast Cancer Res Treat. 2006;95:279-93.

5. Bolster MJ, Peer PG, Bult P, Thunnissen FB, Schapers RF, Meijer JW, et al. Risk factors for non-sentinel lymph node metastases in patients with breast cancer. The outcome of a multi-institutional study. Ann Surg Oncol. 2007;14(1):181-9. Epub 2006 Oct 7.

6. Fleming FJ, Kavanagh D, Crotty TB, Quinn CM, McDermott EW, O'Higgins N, et al. Factors affecting metastases to non-sentinel lymph nodes in breast cancer. J Clin Pathol. 2004;57(1):73-6.

7. Visser M, Jiwa M, Horstman A, Brink AA, Pol RP, van Diest P, et al. Intra-operative rapid diagnostic ethod based on CK19 mRNA expression for the detection of lymph node metastases in breast cancer. Int J Cancer. 2008;122:2562-7.

8. Schem C, Maass N, Bauerschlag DO, Carstensen MH, Löning T, Roder C, et al. One-step nucleic acid amplification-a molecular method for the detection of lymph node metastases in breast cancer patients; results of the German study group. Virchows Arch. 2009;454:203-10.

9. Tamaki Y, Akiyama F, Iwase T, Kaneko T, Tsuda H, et al. Molecular detection of lymph node metastases in breast cancer patients: results of a multicenter trial using the one-step nucleic acid amplification assay. Clin Cancer Res. 2009:15:2879-84.

10. Tsujimoto M, Nakabayashi K, Yoshidome K, Kaneko T, Iwase T, Akiyama F, et al. One-step nucleic acid amplification for intraoperative detection of lymph node metastasis in breast cancer patients. Clin Cancer Res. 2007;13:4807-16.

11. Buglioni S, Di Filippo F, Terrenato I, Casini B, Gallo E, Marandino F, et al. Quantitative molecular analysis of sentinel lymph node may be predictive of axillary node status in breast cancer classified by molecular subtypes. PLoS One. 2013;8(3), e58823.

12. Ianosos A, Schrg D, Ray GV, Panageas KS. How to build and interprate a nomogram for cancer program. J Clin Oncol. 2008;16:1364-70.

13. Chen X, Sun L, Cong Y, Zhang T, Lin Q, Meng Q, et al. Baseline staging tests based on molecular subtype is necessary for newly diagnosed breast cancer. J Exp Clin Cancer Res. 2014;33:28.

14. Jiang Z, Guo J, Shen J, Jin M, Xie S, Wang L. The role of estrogen receptor alpha in mediating chemoresistance in breast cancer cells. J Exp Clin Cancer Res. 2012;31:42.

15. Degnim AC, Reynolds C, Pantvaidya G, Zakaria S, Hoskin T, Barnes S, et al. Nonsentinel node metastasis in breast cancer patients: assessment of an existing and a new predictive nomogram. Am J Surg. 2005;190:543-50.

16. Krag DN, Anderson SJ, Julian TB, Brown AM, Harlow SP, et al. Sentinel-lymph-node resection compared with conventional axillary-lymph-node dissection in clinically node-negative patients with breast cancer: overall survival findings from the NSABP B-32 randomised phase 3 trial. N. Lancet Oncol. 2010;11(10):927-33.

17. Veronesi U, Viale G, Paganelli G, Zurrida S, Luini A, Galimberti V, et al. Sentinel lymph node biopsy in breast cancer: ten-year results of a randomized controlled study. Ann Surg. 2010;251(4):595-600.

18. Lyman GH, Temin S, Edge SB, Newman LA, Turner RR, Weaver DL, et al. Sentinel lymph node biopsy for patients with early-stage breast cancer: American Society of Clinical Oncology clinical practice guideline update. J Clin Oncol. 2014;32(13):1365-83.

19. Giuliano AE, Hunt KK, Ballman KV, Beitsch PD, Whitworth PW, Blumencranz PW, et al. Axillary dissection vs no axillary dissection in women with invasive breast cancer and sentinel node metastasis: a randomized clinical trial. JAMA. 2011;305(6):569-75.

20. Latosinsky S, Berrang TS, Cutter CS, George R, Olivotto I, Julian TB, et al. Axillary dissection versus no axillary dissection in women with invasive breast cancer and sentinel node metastasis. J Can Chir, vol 55, №1 fevrier 2012.

21. Hoffmann J, Souchon R, Lebeau A, Öhlschlegel C, Gruber G, Rageth C, et al. German, Austrian and Swiss consensus conference on the diagnosis and local treatment of the axilla in breast cancer. AGO; DGS; SGS; ÖGS. Eur J Cancer. 2013:49(10):2277-83.

22. Galimberti V, Cole BF. Axillary versus sentinel-lymph-node dissection for micrometastatic breast cancer-authors' reply. Lancet Oncol. 2013;14(7):e251-2.

23. Rahusen FD, Torrenga $H$, van Diest PJ, Pijpers $R$, van der Wall E, Licht J, et al. Predictive factors for metastatic involvement of nonsentinel nodes in patients with breast cancer. Arch Surg. 2001;136:1059e63.

24. Viale G, Maiorano E, Mazzarol G, Zurrida S, Galimberti V, Luini A, et al. Histologic detection and clinical implications of micrometastasis in axillary sentinel lymph nodes for patients with breast carcinoma. Cancer. 2001;92:1378e84.

25. Fisher B, Anderson S, Bryant J, Margolese RG, Deutsch M, Fisher ER, et al. Twenty-year follow-up of a randomized trial comparing total mastectomy, lumpectomy, and lumpectomy plus irradiation for the treatment of invasive breast cancer. N Engl J Med. 2002;347(16):1233-41.

26. Pepels MJ, de Boer M, Bult P, van Dijck JA, van Deurzen CH, Menke-Pluymers $M B$, et al. Regional recurrence in breast cancer patients with sentinel node micrometastases and isolated tumor cells. Ann Surg. 2012;255(1):116-21.

27. Mittendorf EA, Hunt KK, Boughey JC, Bassett R, Degnim AC, Harrell R, et al. Incorporation of sentinel lymph node metastasis size into a nomogram predicting nonsentinel lymph node involvement in breast cancer patients with a positive sentinel lymph node. Ann Surg. 2012;255(1):109-15.

28. Houvenaeghel G, Nos C, Mignotte H, Classe JM, Giard S, Rouanet P, et al. Micrometastases in sentinel lymph node in a multicentric study: predictive factors of nonsentinel lymph node involvement. Groupe des Chirurgiens de la Federation des Centres de Lutte Contre le Cancer. J Clin Oncol. 2006:24:1814-22.

29. Cserni G, Gregori D, Merletti F, Sapino A, Mano MP, Ponti A, et al. Meta-analysis of non-sentinel node metastases associated with micrometastatic sentinel nodes in breast cancer. Br J Surg. 2004;91:1245e52.

30. Wong SL, Edwards MJ, Chao C, Tuttle TM, Noyes RD, Woo C, et al. Predicting the status of the nonsentinel axillary nodes. Arch Surg. 2001;136:563-8.

31. Reynolds C, Mick R, Donohue JH, Grant CS, Farley DR, Callans LS, et al. Sentinel lymph node biopsy with metastasis: can axillary dissection be avoided in some patients with breast cancer? J Clin Oncol. 1999;17:1720-6.

32. Joseph KA, El-Tamer M, Komenaka I, Troxel A, Ditkoff BA, Schnabel F. Predictors of nonsentinel node metastasis in patients with breast cancer after sentinel node metastasis. Arch Surg. 2004;139:648-51. 
33. Turner RR, Chu K, Qi K, Hansen NM, Glass EC, Giuliano AE. Pathologic features associated with nonsentinel lymph node metastases in patients with metastatic breast carcinoma in a sentinel lymph node. Cancer. 2000;89:574-81.

34. Kamath VJ, Giuliano R, Dauway EL, Cantor A, Berman C, Ku NN, et al. Characteristics of the sentinel lymph node in breast cancer predict further involvement of higher-echelon nodes in the axilla: a study to evaluate the need for complete axillary lymph node dissection. Arch Surg. 2001;136:688-92.

35. Ozmen V, Karanlik H, Cabioglu N, Igci A, Kecer M, Asoglu O, et al. Factors predicting the sentinel and nonsentinel lymph node metastases in breast cancer. Breast Cancer Res Treat. 2006;95:1-6.

36. Carter $\mathrm{CL}$, Allen $\mathrm{C}$, Henson DE. Relation of tumor size, lymph node status, and survival in 24,740 breast cancer cases. Cancer. 1989;63:181-7.

37. Coutant C, Olivier C, Lambaudie E, Fondrinier E, Marchal F, Guillemin F, et al. Comparison of models to predict nonsentinel lymph node status in breast cancer patients with metastatic sentinel lymph nodes: a prospective multicenter study. J Clin Oncol. 2009;27(17):2800-8.

38. Van Zee KJ, Manasseh DM, Bevilacqua JL, Boolbol SK, Fey JV, Tan LK, et al. A nomogram for predicting the likelihood of additional nodal metastases in breast cancer patients with a positive sentinel node biopsy. Ann Surg Oncol. 2003;10:1140-51.

39. Kohrt HE, Olshen RA, Bermas HR, Goodson WH, Wood DJ, Henry S, et al. New models and online calculator for predicting non-sentinel lymph node status in sentinel lymph node positive breast cancer patients. BMC Cancer. 2008;8:66.

40. Pal A, Provenzano E, Duffy SW, Pinder SE, Purushotham AD. A model for predicting non-sentinel lymph node metastatic disease when the sentinel lymph node is positive. Br J Surg. 2008;95:302-9.

41. Barranger E, Coutant C, Flahault A, Delpech Y, Darai E, Uzan S, et al. An axille scoring system to predict non-sentinel lymph node status in breast cancer patients with sentinel lymph node involvement. Breast Cancer Res. 2005;91:113-9.

42. Van la Parra RF, Peer PG, Ernst MF, Bosscha K. Meta-analysis of predictive factors for non-sentinel lymph node metastases in breast cancer patients with a positive SLN. Eur J Surg Oncol. 2011;37(4):290-9.

43. Koca B, Kuru B, Ozen N, Yoruker S, Beh Y. A breast cancer nomogram for prediction of non-sentinel node metastasis- validation of fourteen existing models. Asian Pac J Cancer Prev. 2014;15(3):1481-8.

\section{Submit your next manuscript to BioMed Central and take full advantage of:}

- Convenient online submission

- Thorough peer review

- No space constraints or color figure charges

- Immediate publication on acceptance

- Inclusion in PubMed, CAS, Scopus and Google Scholar

- Research which is freely available for redistribution 